\title{
Climate change trends in the forest-meadow zone of the Middle Urals and their impact on technological approaches to corn cultivation
}

\author{
A.E. Panfilov*, P.Yu. Ovchinnikov, and E.L. Tikhanskaya \\ FSBSI «Ural Federal Agrarian Research Center of the Ural Branch of the Russian Academy of \\ Sciences» st. Belinsky, 112-a, Po Box 269, 620142, Yekaterinburg, Russia
}

\begin{abstract}
The results of the analysis of long-term trends in changes in individual climatic characteristics and variations in weather conditions of the growing season in the forest-meadow zone of the Middle Urals for the period from 1958 to 2020 are presented, their influence on the choice of hybrids and some elements of corn cultivation technology are estimated. As a result of calculating the linear trend, a statistically proven trend has been established to increase the sum of active temperatures above $10{ }^{\circ} \mathrm{C}$ for May - September. At the same time, random fluctuations of the analyzed parameters over the years have a direct impact on corn development and productivity, and the limiting factor is the lower limit of these fluctuations, the values of which increase throughout the analyzed period. Nevertheless, the variation over the years remains strong, and the lower limit of these fluctuations does not reach the minimum level for the stable maturation of early-maturing corn hybrids. Therefore, for the conditions of the Middle Urals, the previous recommendations concerning the selection of corn hybrids for early maturity, cold resistance and drought resistance remain relevant. At the same time, the revealed climatic trend allows to predict an increase in the probability of obtaining feed with a high content of exchange energy, which characterizes it as positive one.
\end{abstract}

\section{Introduction}

Corn is the most important agricultural crop with a high yield potential and versatile use [1]. The main limiting factor affecting corn growth and development is the low heat provision of the growing season [2,3]. Heat resources belong to uncontrolled factors of plant growth and development, so the main way to weaken their limiting influence is to develop and implement adaptive technologies for corn cultivation [4]. One of the conditions for corn adaptation to the climate of the region is the creation and selection of ultra-early hybrids: stable maturation to milk-wax and wax ripeness in the forest-meadow zone is expected when using samples of a narrow range of early ripeness (up to $120 \mathrm{FAO}$ units); in addition, for the sustainable production of high-energy feed from corn grain in the Ural region, a necessary condition is to postpone the sowing dates to the first decade of May.

\footnotetext{
Corresponding author: al_panfilov@mail.ru
} 
This ensures a more efficient use of heat, moisture and light resources by plants, an increase in silage and grain productivity, a decrease and stabilization of the harvest moisture content of grain $[5,6]$. Negative factors that must be considered when implementing this technique are the negative reaction of individual hybrids to changes in the temperature regime during the juvenile period and the deterioration of the phytosanitary situation. The influence of these factors can be offset by the selection of cold-resistant hybrids and the use of effective means and schemes of plant protection [7]. Consequently, in the conditions of the Middle Urals, the main elements of corn cultivation technology are aimed at adapting corn to regular and periodic heat shortages.

The connection of the technology with the climatic conditions of the natural zone raises the question of possible adjustments due to global climate change [8, 9, 10]. From the general climate model of M. E. Mann [11], describing the increase in the average annual air temperature on the planet since about the end of the 50s of the XX century, questions arise about how stable the trends identified by the author are in relation to individual regions [12, $13,14]$ and whether they should be considered when justifying agricultural technologies.

As a result of studies conducted on the territory of the Volga region, the NonChernozem zone, the Central Chernozem region, it was revealed that according to such characteristics as the sum of active temperatures, precipitation, average air temperature and hydrothermal coefficient (HTC) for the growing season, there is a tendency to change, as well as a correlation with the yield and quality of products for cereals and a number of forage crops [15, 16, 17]. M.Yu. Ksenofontov and D.A. Polzikov [18] assess the impact of climate change on agricultural productivity as moderately negative. The authors recommend to carry out certain structural and technological shifts (to increase the area of reclaimed land, to change the structure of crops and tillage methods). According to Yu.R. Ivanova et al. [19], there is an increase in anomalies of the average annual air temperature in the territory of the Middle Urals, and the period after 1970 is characterized by the most intense warming and a decrease in the number of negative deviations. The increase in the annual precipitation amount is also comparable with the data averaged for the territory of Russia. In recent decades, abnormally wet years have become more common.

The dependence of agricultural production on climate is realized not directly, but indirectly, through weather conditions that are subject to strong variation, both during individual periods and in a multi-year aspect. In areas of risky farming, the selection of varieties, hybrids and agricultural technologies should be aimed at adapting crops not to optimal, but to the minimum values of limiting environmental factors [20]. Therefore, when analyzing climate trends, it is necessary to consider not only the long-term trend, but also the nature of the variation of meteorological parameters (average air temperature, sum of temperatures and precipitation, HTC).

The purpose of the research is to study climate trends and their variation in the forestmeadow zone of the Middle Urals to assess the impact of regional climate change on the selection of hybrids and some elements of corn cultivation technology.

\section{Materials and methods}

The research was carried out in the Ural Agricultural Research Center of the Ural Branch of the Russian Academy of Sciences as part of the State task of the Ministry of Education and Science. For statistical analysis of weather conditions of the forest-meadow zone of the Sverdlovsk region for the period from 1958 to 2020, data from the archive of the Department of agriculture and feed production of the Ural Research Institute of Agriculture Branch of the FSBSI UrFARC UrB RAS were used.

Statistical hypotheses were tested using methods of variance, correlation, and regression analysis. The reliability of the differences between the group averages was judged by the 
Fisher criterion $(F)$. The significance of the correlation and regression coefficients was estimated by the value of the errors of these parameters $\left(S_{r}, S_{b}\right)$ and the Student's criterion $(t)$. The significance level of critical values of statistical parameters is $p=0.05$. For the analysis, the values of hydrothermal factors for the period from May to September were used, which, in accordance with the recommendations for optimal crop sowing and harvesting [21], coincides with the period of active corn growing in the Middle Urals.

\section{Results and discussion}

According to the regression analysis, a linear trend of increasing the sum of temperatures above $10{ }^{\circ} \mathrm{C}$ in the forest-meadow zone of the Middle Urals for the period from 1958 to 2020 (63 years) was noted. The calculated increase in the sum of temperatures on average for the year, which corresponds to the regression coefficient, is $3.87^{\circ} \mathrm{C}$ (Fig. 1).

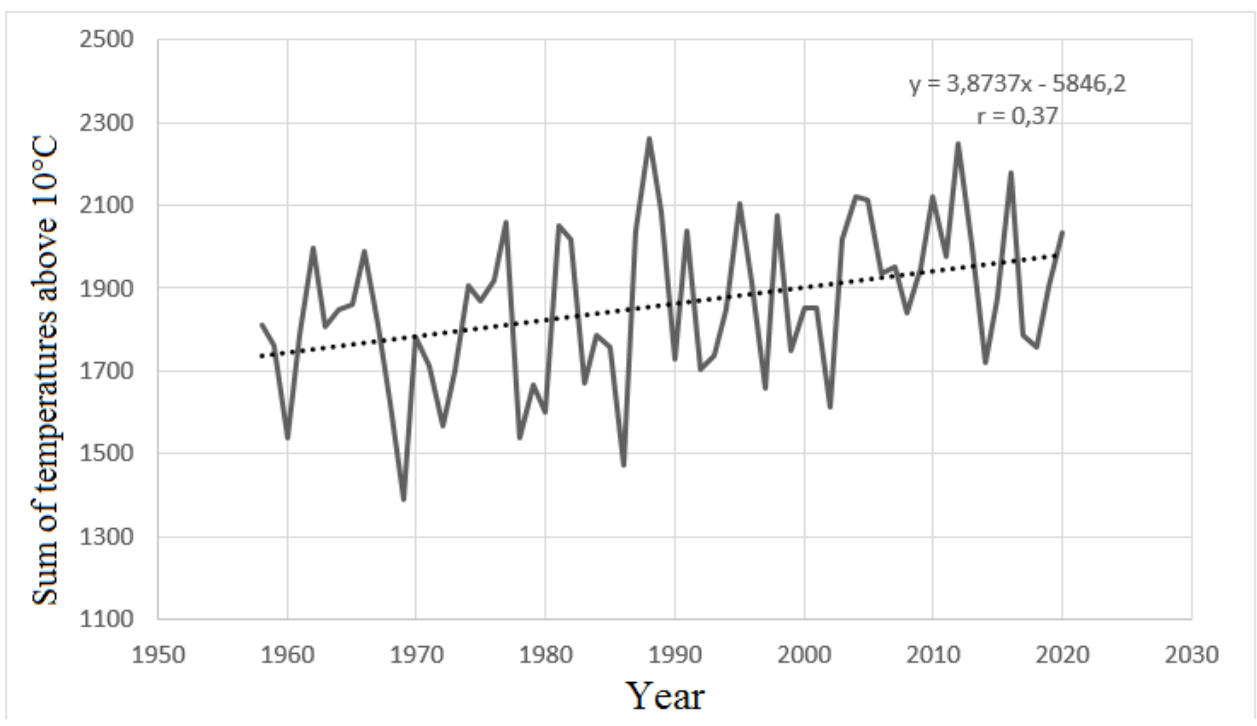

Fig. 1. Linear trend of the sum of active temperatures in the forest-meadow zone of the Middle Urals (1958-2020).

At the same time, the correlation for the trend is characterized as average $(r=0.37)$, but statistically proven by the Student's criterion $\left(t_{r}>\mathrm{t}>_{05}\right)$ (Table 1$)$.

The total increase in the seasonal sum of temperatures for 63 years according to the calculation of the regression equation was 240.2 degrees, which reflects an increase in the indicator from 1739 to 1979 degrees. It should be noted that the main classes of corn hybrids in terms of early ripeness (early-ripening, medium-early, medium-ripening, etc.) differ in the need for the sum of active temperatures by 150-200 degrees [22]. This suggests the possibility of expanding the recommended range of early maturity of corn hybrids to 120-150 FAO units.

Table 1. Results of correlation and regression analysis of the sums of active temperatures above 10 degrees for May-September in the forest-meadow zone of the Middle Urals (1958-2020).

\begin{tabular}{|c|c|}
\hline Indicator & $\begin{array}{c}\text { Results of correlation and } \\
\text { regression analysis }\end{array}$ \\
\hline $\begin{array}{c}\text { The average amount of } \mathrm{t}>10^{\circ} \mathrm{C}, \\
\text { degrees }\end{array}$ & 1858 \\
\hline
\end{tabular}




\begin{tabular}{|c|c|}
\hline $\begin{array}{c}\text { Estimated increase for the } \\
\text { analyzed period, degrees }\end{array}$ & 240.2 \\
\hline Regression coefficient $\mathrm{b}$ & 3.87 \\
\hline Correlation coefficient $\mathrm{r}$ & 0.37 \\
\hline Student's criterion $\mathrm{t}_{\mathrm{r}}\left(\mathrm{t}_{05}=2.00\right)$ & 3.14 \\
\hline
\end{tabular}

The established trend contradicts the Report on the peculiarities of the climate on the territory of the Russian Federation for 2019, which notes the statistical insignificance (P $<0.01$ ) of the linear trend of the surface air temperature for the winter, summer and autumn periods in the Ural region for 1976-2019. [23]. One of the reasons for this discrepancy may be the strong fluctuations in heat resources over the years against the background of the climate trend.

To identify the ratio of the contribution of the trend and random fluctuations in the amounts of active temperatures in the forest-meadow zone, a one-factor variance analysis was carried out, for this purpose, data for 63 years were divided into 8 groups (seven groups of eight years and one group including seven years). The average sums of temperatures in the groups reflect a long-term climatic trend, and the variation within the groups describes the fluctuations in the weather, the influence of which determines the corn growth and development (Table 2).

Table 2. Results of the variance analysis of the sums of active temperatures above 10 degrees for May-September in the forest-meadow zone of the Middle Urals (1958-2020).

\begin{tabular}{|c|c|}
\hline Indicator & Results of the variance analysis \\
\hline Intergroup variance & 66560.1 \\
\hline Intra-group variance & 32454.2 \\
\hline Fischer's criterion $\mathrm{F}_{\mathrm{f}}\left(\mathrm{F}_{05}=2.18\right)$ & 2.05 \\
\hline
\end{tabular}

The obtained data showed that the inter-group variance exceeds the intra-group one. Nevertheless, in the forest-meadow zone for a given period of time, differences in eightyear groups have not been proven by the Fisher's criterion. This suggests that, despite the statistical significance of the linear trend, the decisive role in assessing the provision of corn with heat does not belong to long-term climatic characteristics, but to the actually observed weather component. It is obvious that for guaranteed ripening of corn to economically significant phases of development, the lower limit of fluctuations in the amounts of active temperatures should be considered as the main limiting factor. The analysis of the intra-group variation of heat resources showed that the minimum and maximum values of the sum of temperatures above $10{ }^{\circ} \mathrm{C}$ for each of the groups for the analyzed period show a tendency to increase $r=0.79$ and 0.73 , respectively (Table 3 ).

Table 3. Analysis of intra-group variation of the sum of temperatures above $10^{\circ} \mathrm{C}$ in the forestmeadow zone of the Middle Urals (1958-2020).

\begin{tabular}{|c|c|c|c|c|}
\hline \multirow{2}{*}{ Groups of years } & \multicolumn{2}{|c|}{ Sums of temperatures above $10{ }^{\circ} \mathrm{C}$, degrees } & \multirow{2}{*}{$\mathrm{V}, \%$} \\
\cline { 2 - 4 } & minimum & maximum & average & \\
\hline $1958-1965$ & 1540.7 & 1998 & 1801.55 & 7.09 \\
\hline $1966-1973$ & 1390.1 & 1987.5 & 1696.363 & 10.49 \\
\hline $1974-1981$ & 1537.4 & 2058.9 & 1825.463 & 10.89 \\
\hline $1982-1989$ & 1472.6 & 2260.6 & 1885.788 & 13.65 \\
\hline $1990-1997$ & 1659.3 & 2105.1 & 1841.988 & 8.93 \\
\hline
\end{tabular}




\begin{tabular}{|c|c|c|c|c|}
$1998-2005$ & 1615 & 2119.2 & 1924.663 & 9.65 \\
\hline $2006-2013$ & 1840.4 & 2249.1 & 2003.925 & 6.31 \\
\hline $2014-2020$ & 1720 & 2178.1 & 1893.529 & 8.68 \\
\hline $\mathrm{r}$ & 0.79 & 0.73 & 0.78 & -0.22 \\
\hline $\mathrm{t}_{05} 2.45$ & 3.26 & 2.58 & 3.03 & 0.58 \\
\hline
\end{tabular}

In addition, there is a tendency to decrease the coefficients of intra-group variation (V) of the analyzed factor, which indicates a slight increase in stability in the provision of plants with heat, but it is not proven by the Student's criterion.

Since corn belongs to mesophytes according to moisture requirements, one of the limiting factors for it is considered to be water availability. According to the regression coefficient (linear trend), the estimated increase in precipitation during the growing season is $1.2 \mathrm{~mm}$ per year, and $75.6 \mathrm{~mm}$ for the entire period (Table 4). Due to the high variation over the years, the trend is characterized by a low correlation coefficient, but it is proved by the Student's criterion $\left(t_{r}<\mathrm{t}_{05}\right)$ (Figure 2).

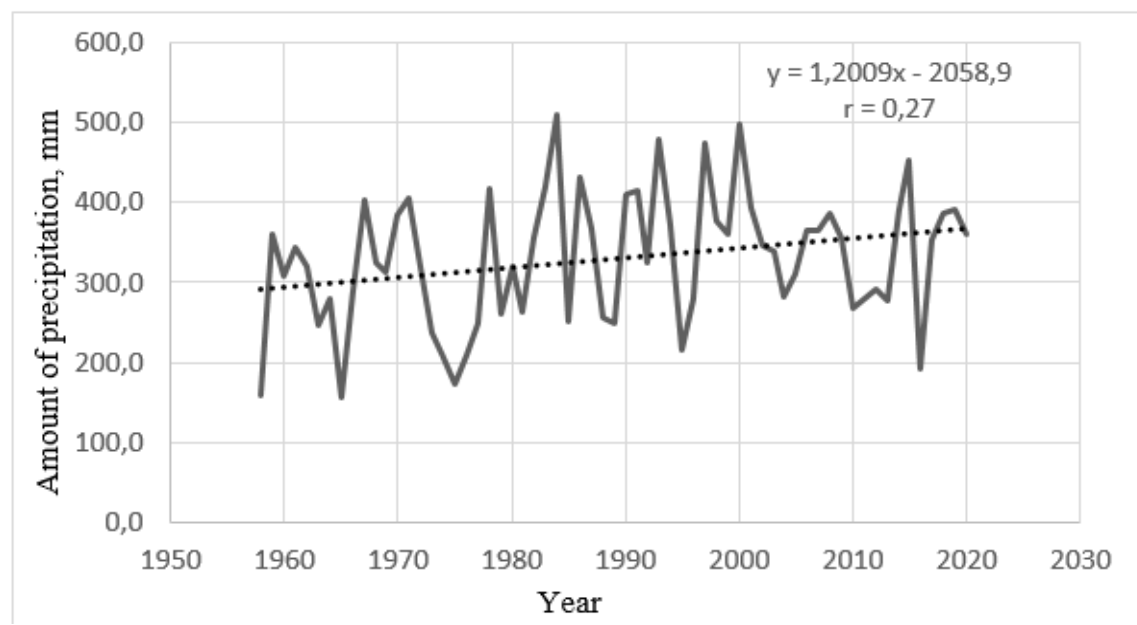

Fig. 2. Linear trend of amount of precipitation in the forest-meadow zone of the Middle Urals.

Table 4. Results of correlation and regression analysis of water availability for May-September in the forest-meadow zone of the Middle Urals (1958-2020).

\begin{tabular}{|l|c|}
\hline \multicolumn{1}{|c|}{ Indicator } & $\begin{array}{c}\text { Results of correlation and } \\
\text { regression analysis }\end{array}$ \\
\hline Average amount of precipitation, $\mathrm{mm}$ & 329.8 \\
\hline Estimated increase for the analyzed period, $\mathrm{mm}$ & 75.6 \\
\hline Regression coefficient $\mathrm{b}$ & 1.2 \\
\hline Correlation coefficient $\mathrm{r}$ & 0.27 \\
\hline Student's criterion $\mathrm{t}_{\mathrm{r}}(\mathrm{t} 05=2.00)$ & 2.16 \\
\hline
\end{tabular}

The variance analysis confirms the tendency to increase the water availability (Table 5). Subsequently, the differences between the groups are proved by the Fisher's criterion $\left(\mathrm{F}_{\mathrm{f}}<\mathrm{F}_{05}\right)$.

Table 5. Results of variance analysis of water availability for May-September in the forest-meadow zone of the Middle Urals (1958-2020).

\begin{tabular}{|c|c|}
\hline Indicator & Results of the variance analysis \\
\hline Intergroup variance & 14126.4 \\
\hline Intra-group variance & 5871.9 \\
\hline
\end{tabular}




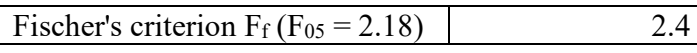

The thesis that the productivity of crops is limited by the lower limits of the variation of natural factors is also applicable to the moisture supply of the growing season. Judging by the values of the variation coefficient, in most cases there is a strong variation in the amount of precipitation during the growing season by groups of years, and the correlation coefficient indicates an average downward trend of this indicator (Table 5).

Table 5. Analysis of intra-group variation of the amount of precipitation in the forestmeadow zone of the Middle Urals (1958-2020).

\begin{tabular}{|c|c|c|c|c|}
\hline period & minimum & maximum & average & $\mathrm{k}-\mathrm{V} \%$ \\
\hline $1958-1965$ & 155.2 & 360.8 & 271.75 & 29.24 \\
\hline $1966-1973$ & 236.4 & 406.4 & 334.4 & 21.1 \\
\hline $1974-1981$ & 173.6 & 418.0 & 262.1 & 29.4 \\
\hline $1982-1989$ & 248.6 & 509.9 & 355.0 & 34.3 \\
\hline $1990-1997$ & 215.1 & 478.6 & 371.4 & 25.0 \\
\hline $1998-2005$ & 282.9 & 497.2 & 363.4 & 17.8 \\
\hline $2006-2013$ & 267.7 & 385.7 & 323.3 & 17.2 \\
\hline $2014-2020$ & 190.8 & 453.4 & 360.9 & 22.6 \\
\hline $\mathrm{r}$ & 0.45 & 0.40 & 0.61 & -0.53 \\
\hline $\mathrm{t}_{\mathrm{r}}\left(\mathrm{t}_{05}=2,45\right)$ & 1.23 & 1.08 & 1.91 & 1.53 \\
\hline
\end{tabular}

The minimum values of moisture availability for groups of years are in the range from 155.2 to $282.9 \mathrm{~mm}$, and according to the value of the correlation coefficient $(\mathrm{r}=0.45)$, there is an average tendency to increase these values. The maximum values of the groups of years vary in the range of $360.8-509.9 \mathrm{~mm}$ with a tendency to their increase, expressed in an average degree (coefficient $r=0.40$ ). Nevertheless, judging by the value of the Student's criterion, the studied tendencies are not proven at the $5 \%$ significance level.

The demand of corn for moisture in different periods of growth and development is not the same [24]. It consumes the greatest amount of moisture for 30 days, starting 10 days before the panicle ear formation and until the stage of milk ripeness [25]. In the forestmeadow zone of the Middle Urals, the critical period of water consumption for ultra-early corn hybrids is observed in July [26]. The correlation and regression analysis carried out did not reveal statistically proven trends in changes in water availability for individual months (Table 6).

Table 6. Results of correlation and regression analysis of water availability by month.

\begin{tabular}{|c|c|c|c|c|c|}
\hline \multirow{2}{*}{ Indicator } & \multicolumn{5}{|c|}{ Month } \\
\cline { 2 - 6 } & May & June & July & August & September \\
\hline $\mathrm{r}$ & 0.133 & 0.128 & 0.142 & 0.185 & 0.068 \\
\hline $\mathrm{b}$ & 0.180 & 0.258 & 0.342 & 0.379 & 0.105 \\
\hline $\mathrm{t}_{\mathrm{r}}\left(\mathrm{t}_{05}=2.00\right)$ & 1.05 & 1.01 & 1.12 & 1.47 & 0.53 \\
\hline
\end{tabular}

\section{Conclusions}

Thus, the analysis of long-term trends in changes in economically significant hydrothermal factors in the Middle Urals from 1958 to 2020 showed a significant increase (by 240.2 degrees) in the amounts of active temperatures for the period from May to September. At the same time, random fluctuations of the analyzed parameters over the years have a direct impact on corn development and productivity, and the limiting factor is the lower limit of these fluctuations, the values of which increased throughout the analyzed period. In 
addition, the analysis of the precipitation amount revealed statistically proven tendencies to increase water availability, but only for the growing season as a whole, and not for individual months. Nevertheless, the variation over the years remains strong, and the lower limit of these fluctuations does not reach the minimum level for the stable maturation of early-maturing corn hybrids. Therefore, for the conditions of the Middle Urals, the previous recommendations concerning the selection of corn hybrids for early maturity, cold resistance and drought resistance remain relevant. At the same time, the revealed climatic trend allows to predict an increase in the probability of obtaining feed with a high content of exchange energy, which characterizes it as positive one.

\section{References}

1. S.K. Mingalev, I.V. Surin, Agrarian Bulletin of the Urals 9 (127), 14-17 (2014)

2. D.I. Eremin, E.A. Demin, Agrarian Bulletin of the Urals 12 (166), 9-15 (2017)

3. N.N. Zezin, M.A. Namyatov, V.R. Laptev, Forage production 11, 25-28 (2015)

4. S.K. Mingalev, V.R. Laptev, G.S. Kuznetsova, L.G. Svechina, Agrarian Bulletin of the Urals 3 (45), 60-62 (2008)

5. I.V. Surin, S.K. Mingalev, Agrarian Bulletin of the Urals, 8 (126), 61-63 (2014)

6. A.E. Panfilov, E.S. Ivanova, N.I. Kazakova, E.S. Pestrikova, Intensive technology of corn cultivation for the production of high-energy feed, Scientific projects of the South Ural State Agrarian University, 87-89 (Chelyabinsk: FSBEI HE South-Ural SAU, 2016)

7. P.Yu. Ovchinnikov, Agro-industrial complex of Russia 5 (26), 775-780 (2019)

8. M. Helbig, J.M. Waddington, S.K. Carey, P.A. Moore, E.M. Nicholls et al., Nature Climate Change 10 (6) (2020) DOI: 10.1038/s41558-020-0763-7

9. K. Marvel, B.I. Cook, C.J.W. Bonfils et al., Nature 569 (1), 59-65 (2019) DOI:10.1038/s41586-019-1149-8.

10. Y. Tramblay, A. Koutroulis, L. Samaniego, S.M. Vicente-Serrano, F. Volaire et al. Earth-Science Reviews 210, $103348 \quad$ (2020) DOI: 10.1016/J.EARSCIREV.2020.103348

11. M.E. Mann, R.S. Bradley, M.K. Hughes, Nature 392, 779-787 (1998)

12. Y. Xu., D. Zaelke, J.M. Guus, G.J.M. Velders, V. Ramanathan, Climate Policy 16 (5), 109-125 (2016) DOI: 10.1201/b20720-9

13. D. Woolf, D. Solomon, J. Lehmann, Climate Policy 18(10), 1260-1270 (2018) DOI: 10.1080/14693062.2018.1427537

14. Chiara Consolaro C., Rasmussen T. L., Panieri G., Mienert J., Climate of the Past, 11 (5), 669-685 (2015) DOI: 10.5194/cp-11-669-2015

15. N.D. Konovalov, S.N. Konovalov, Agriculture 6, 36-37 (2008)

16. S.N. Nemtsev, R.B. Sharipova, Agriculture, 3-5 (2012)

17. G.V. Blagoveshchensky, Forage production, 10, 6-8 (2008)

18. M.Yu. Ksenofontov, D.A. Polzikov, Problems of forecasting, 3, 82-92 (2020)

19. Yu.R. Ivanova, N.V. Skok, A.M. Evdokimova, Success of modern Natural Science 3, 78-84 (2020)

20. A.A. Zhuchenko, Adaptive potential of cultivated plants, Chisinau: Stiinza, 767 (1988)

21. N.N., A.E. Panfilov, A.E. Nagibin, M.A. Tormozin, M.A. Namyatov, P.A. Postnikov, A.P. Kolotov, N.I. Kazakova, A.A. Zyryantseva, E.L. Tikhanskaya, Modern feed 
production of the Urals (monograph); under the general editorship of N.N. Zezin, A. E. Panfilova. Yekaterinburg: Information and Advertising Agency of the Ural Trading Company, 265 (2019)

22. V.A. Voloshin, Agrarian Bulletin of the Urals, 9 (75), 57-59 (2010)

23. M.Yu. Bardin, V.I. Egorov, A.M. Nikolaeva, T.V. Platova, E.Ya. Rankova et al., Report on the peculiarities of the climate on the territory of the Russian Federation for 2019, 97 (Moscow: Roshydromet, 2020)

24. Tineka, Burkhead, Vincent, Klink, AIMS Agriculture and Food 3 (4), 406-425 (2018)

25. A.M. Loginova, V.S. Ilyin, G.V. Getz, Successes of modern Natural Science 6, 32-36 (2018)

26. N.N. Zezin, M.A. Namyatov, Feed production 3, 11-15 (2018) 